УДК 615.322:615.072:615.451.16

РАЗРАБОТКА ПОДХОДОВ К СТАНДАРТИЗАЦИИ ЦВЕТКОВ БЕССМЕРТНИКА

ПЕСЧАНОГО (HELICHRYSUM ARENARIUM (L.) MOENCH) В PACTИTEЛЬНЫХ СМЕСЯХ.

\author{
(C) 2013 Гудзенко А.В., Цуркан А.А.
}

ГУ «Институт фармакологии и токсикологии НАМН Украины», г. Киев.

Определен маркер по наличию и количественному содержанию которого возможна качественная и количественная стандартизация в растительных смесях цветков бессмертника песчаного. В качестве маркера данного сырья может быть использован флавоноид апигенин. С использования метода ВЭЖХ разработана методика определения флавоноида апигенина в сырье и растительных смесях цветков бессмертника песчаного. Содержание апигенина в сырье цветков растения лежит в пределах от $0,1453 \pm 0,0068 \%$ до $0,1657 \pm 0,0085 \%$ в пересчете на высушенное сырье. Показана возможность проведения качественной и количественной стандартизации цветков бессмертника песчаного по содержанию флавоноида апигенина в присутствии биологически активных веществ плодов боярышника колючего, корней алтея лекарственного, корней солодки голой, корней цикория дикого, корней одуванчика лекарственного, шишек хмеля, травы пустырника, листьев и цветков боярышника колючего, травы зверобоя продырявленного и семян льна.

Ключевые слова: цветки бессмертника песчаного, стандартизация, апигенин, многокомпонентные растительные смеси, высокоэффективная жидкостная хроматография

\title{
ELABORATION OF APPROACHES TO THE STANDARTIZ OFATION HELICHRYSUM ARENARIUM (1.) MOENCH IN PLANT MIXTURES
}

\section{A.B. Goudzenko, A.A. Tsourkan}

\section{Institute of pharmacologie and toxocologie of Ukraine, Kiev}

Marker for qualitative and quantitative standardization of Helichrysum arenarium (L.) Moench. flowers in the plant mixtures was determine. As a marker of Helichrysum arenarium Moench. flowers can be used flavonoid apigenin. HPLC method of determination flavonoid apigenin in raw materials and plant mixtures of flowers Helichrysum arenarium (L.) Moench was developed. Contents of apigenin in the raw plant flowers were in the range from $0,1453 \pm 0,0068 \%$ to $0,1657 \pm$ $0,0085 \%$, in terms of the dried materials. It is shown, that the presence and content of apigenin flowers Helichrysum arenarium (L.) Moench can be standardized in the mixtures with the following plant: flowers, leaves and fruits of genus Crataegus L., roots of Althaea officinalis L., roots of Glycyrrhiza glabra L., roots of Cichorium intybus L., roots of Taraxacum officinale Web., cones of Humulus lupulus L., herb of Leonurus cardiaca L., herb of Hypericum perforatum L. and seeds of Linum usitatissimum L.

Key words: Helichrysum arenarium (L.) Moench. flowers, standardization, apigenin, multicomponent plant composition, HPLC

В последние годы в мировой фитотерапии наблюдается тенденция к более широкому использованию многокомпонентных лекарственных средств растительного происхождения (МЛСРП). Существующие в настоящее время методики анализа вышеупомянутых фитопрепаратов в большинстве своем не отвечают современным фармакопейным требованиям, они не являются специфическими, не дают возможности проведения идентификации и определения количественного содержания отдельных компонентов смеси. 
Одно из перспективных направлений дальнейшего совершенствования процедуры стандартизации многокомпонентных фитопрепаратов - использование так называемых «маркерных соединений», или маркеров - веществ, присутствие которых характерно только для определенного лекарственного сырья. Внедрение методик качественного и количественного анализа, основанных на использовании маркеров, имеет не только большое практическое значение, но и существенную научную целесообразность.

При этом следует отметить отличие терминов «хемотаксономический маркер» и «маркер для стандартизации растительных смесей». Выбор маркера для анализа определенного компонента в растительной смеси определяется исключительно составом данной смеси. И поэтому один и тот же компонент может быть стандартизирован в растительных смесях, отличающихся по своему составу, по наличию различных биологически активных веществ [2].

Одним из наиболее распространенных компонентов МЛСРП является бессмертник песчаный $[6,7]$. Это лекарственное сырье стандартизируется согласно ГФ XI по содержанию суммы флавоноидов в пересчете на изосалипурпозид $[1,3,4]$, который наряду с салипурпозидом, является мажоритарным представителем фракции флавоноидов в растении [3, 4]. Исходя из вышесказанного, целесообразным было бы рассмотреть возможность использования именно данных веществ в качестве маркеров цветков бессмертника песчаного. Однако, исходя из того, что изосалипурпозид и салипурпозид являются гликозидами флавоноидов, существуют определенные проблемы при использовании их в качестве маркера данного сырья, поскольку современные сорбенты, применяемые в жидкостной хроматографии, в большинстве своем лишь ограниченно приспособлены к разделению гликозидов флавоноидов. Исходя из этого, считалось целесообразным предложить для стандартизации цветков бессмертника песчаного в растительных смесях альтернативный маркер - флавоновый агликон апигенин, который в значительной концентрации присутствует в данном растительном сырье и обладает широким спектром биологической активности $[5,8-12]$.

Цель исследования - разработать методологию использования флавоноида апигенина в качестве маркера цветков бессмертника песчаного при анализе растительных смесей.

\section{Материалы и методы}

Объектами исследования были следующие лекарственные средства и растительные смеси: цветки бессмертника песчаного в пачках по 50 г (производитель $3 \mathrm{AO}$ «Лектравы», г. Житомир, Украина (серии: 101111, 111211, 30212, 40212); цветки бессмертника песчаного в пачках по 20 г (производитель ЗАО ФФ «Виола», г. Запорожье, Украина (серия 231110)); модельная смесь с содержанием цветков бессмертника песчаного: цветков бессмертника песчаного - 1 г, плодов боярышника колючего - 1 г, корней алтея лекарственного - 1 г, корней солодки голой -1 г, корней цикория - 1 г, корней одуванчика лекарственного - 1 г, соплодий хмеля - 1 г, травы пустырника -1 г, листьев и цветков боярышника колючего -1 г, травы зверобоя - 1 г, семян льна - 1 г; модельная смесь без содержания бессмертника песчаного: плодов боярышника колючего - 1 г, корней алтея лекарственного -1 г, корней солодки голой 1 г, корней цикория -1 г, корней одуванчика лекарственного -1 г, соплодий хмеля -1 г, травы пустырника - 1 г, листьев и цветков боярышника колючего - 1 г, травы зверобоя - 1 г, семян льна -1 г.

Экстракция биологически активных веществ (БАВ) в исследуемых объектах проводилась с использованием 50\% этилового спирта. Выбор данного экстрагента обусловлен его универсальностью, так как мы предполагали возможность использования разработанной нами методики для определения других компонентов исследуемой модельной смеси по содержанию веществ-маркеров с отличной от апегинина гидрофобностью.

Экстракцию БАВ в исследуемых объектах проводили следующим образом: 1 г (точная навеска) измельченного моносырья или 5 г (точная навеска) растительной смеси вносили в коническую колбу, оборудованную обратным холодильником, добавляли 50 мл 50 \% спирта этилового и выдерживали на кипящей водяной бане в течение 45 минут. После этого экстракт охлаждали до комнатной температуры и фильтровали через фильтр «красная лента» в мерную колбу объемом 100 мл. Экстракцию проводили еще раз и доводили объем колбы до 100 мл 50 \% спиртом этиловым. К 5 мл полученного раствора добавляли такое количество воды, чтобы 
концентрация спирта этилового составляла $15 \%$, и пропускали полученный образец через предварительно активированный (метанол 5 мл) и промытый 10 мл воды патрон для твердофазной экстракции "Superclean LC-18 SPE Tubes $2 \mathrm{ml}$ " производства фирмы Supelco (США). Патрон промывали 10 мл $15 \%$ спирта этилового. Пробу из патрона вымывали 10 мл спирта метилового. Полученный аналит концентрировали посредством испарения до объема 5 мл и фильтровали через фильтр с диаметром пор 0,45 мкм.

Хроматографическое изучение исследуемых экстрактов и растворов сравнения апигенина проводили на хроматографе Shimadzu ser. 20, оборудованном диодно-матричным детектором в следующих условиях: колонка Phenomenex Luna C18 (2), размером 250 мм х 4,6 мм, размер частиц 5 мкм, температура колонки $-35^{\circ} \mathrm{C}$, длина волны детектирования -330 нм, скорость потока подвижной фазы - 1 мл/мин, объем инжектирования - 5мкл;

подвижная фаза:

Таблица 1 - Условия хроматографирования

\begin{tabular}{|l|l|l|}
\hline Время хроматографирования (мин.) & Элюент А, \% & Элюент Б, \% \\
\hline $0-5$ & 95 & 5 \\
\hline $5-35$ & $95 \rightarrow 75$ & $5 \rightarrow 25$ \\
\hline $35-40$ & 75 & 25 \\
\hline $40-60$ & $75 \rightarrow 50$ & $25 \rightarrow 50$ \\
\hline $60-65$ & $50 \rightarrow 20$ & $50 \rightarrow 80$ \\
\hline $65-70$ & 20 & 80 \\
\hline $70-85$ & 95 & 5 \\
\hline
\end{tabular}

Элюент А: $0.1 \%$ раствор трифторуксусной кислоты в воде;

Элюент Б: $0.1 \%$ раствор трифторуксусной кислоты в ацетонитриле.

При выполнении работы использовали реактивы: ацетонитрил для градиентного хроматографирования (FLUKA, Германия);трифторуксусную кислоту (FLUKA, Германия); спирт этиловый ректифицированный фармакопейного качества; воду бидистиллированную.

\section{Результаты и их обсуждение}

На рисунке 1 представлены хроматограммы раствора сравнения апигенина (А) и экстракта цветков бессмертника песчаного (Б).

Как можно видеть, время выхода пика апигенина в указанных выше условиях составляет около 33,3 минуты. Данный пик присутствует как на хроматограмме раствора сравнения апигенина, так и на хроматограмме экстракта цветков бессмертника песчаного.

С использованием разработанной методики были проанализированы препараты бессмертника песчаного различных производителей: цветки бессмертника песчаного в пачках по 50 г (производитель: ЗАО «Лектравы», г. Житомир (серии: 101111, 111211, 30212, 40212) и цветки бессмертника песчаного в пачках по 20 г (производитель: ЗАО ФФ «Виола», г. Запорожье (серия 231110)).

Содержание апигенина в разных сериях цветков бессмертника песчаного представлено в таблице 2.

Согласно данным, представленным в таблице 2, во всех пробах был идентифицирован и количественно определен флавоноид апигенин, содержание которого в исследуемом сырье находится в пределах от $0,1453 \pm 0,0068 \%$ до $0,1657 \pm 0,0085 \%$ в пересчете на высушенное сырье.

В данных условиях был проведен анализ растительного сырья, которое часто входит в состав многокомпонентных препаратов бессмертника песчаного, а именно плодов боярышника колючего, корней алтея. 

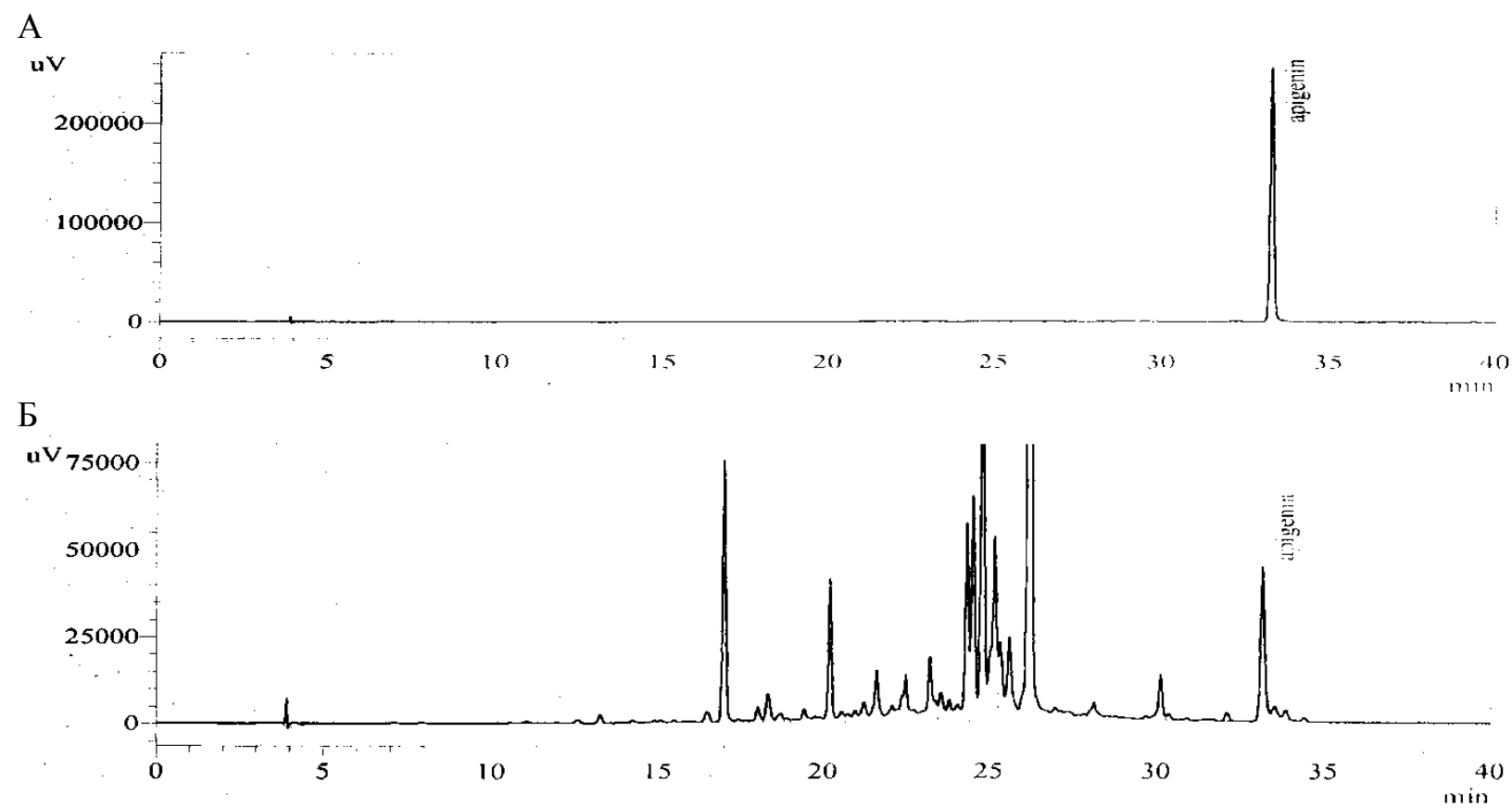

B

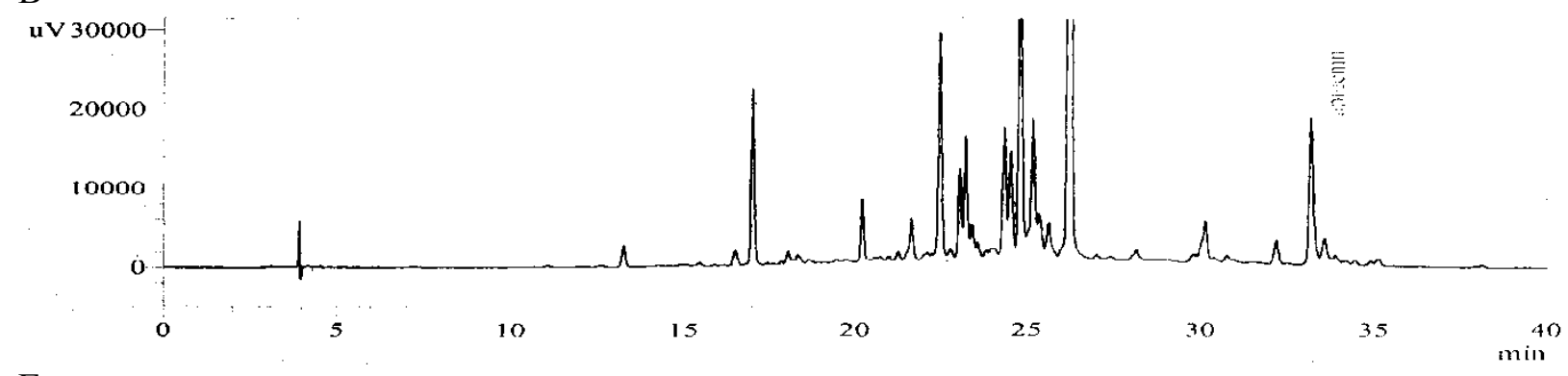

$\Gamma$

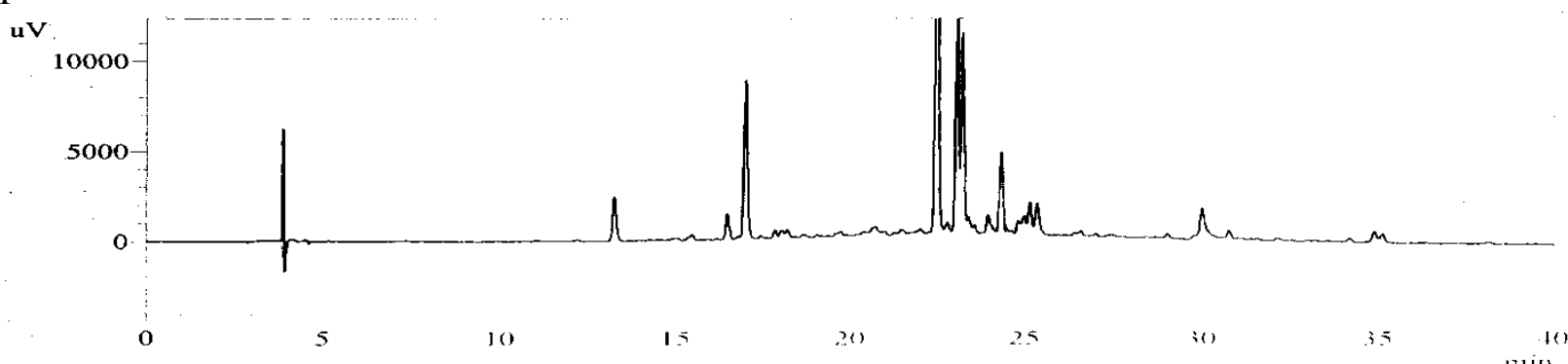

Рисунок 1 - Хроматограммы исследуемых растворов: А - раствора сравнения апигенина; Б экстракта цветков бессмертника песчаного; В - экстракта модельной смеси с содержанием цветков бессмертника; Г - экстракта модельной смеси без содержания цветков бессмертника 
Таблица 2 - Содержание апигенина в исследуемых препаратах бессмертника песчаного.

\begin{tabular}{|l|l|l|l|}
\hline $\begin{array}{l}\text { № } \\
\text { п/п }\end{array}$ & Препарат & $\begin{array}{l}\text { Производитель, } \\
\text { № серии }\end{array}$ & $\begin{array}{l}\text { Содержание апигенина } \\
\text { (в \%) в перерасчете на } \\
\text { высушенное сырье }\end{array}$ \\
\hline 1 & $\begin{array}{l}\text { Цветки бессмертника } \\
\text { песчаного в пачке по 50 г }\end{array}$ & $\begin{array}{l}\text { 3АТ «Лектравы», } \\
\text { серия 111211 }\end{array}$ & $0,1575 \pm 0,0073$ \\
\hline 2 & $\begin{array}{l}\text { Цветки бессмертника } \\
\text { песчаного в пачке по 50 г }\end{array}$ & $\begin{array}{l}\text { 3АТ « «Лектравы», } \\
\text { серия 101111 }\end{array}$ & $0,1570 \pm 0,081$ \\
\hline 3 & $\begin{array}{l}\text { Цветки бессмертника } \\
\text { песчаного в пачке по 50 г }\end{array}$ & $\begin{array}{l}\text { 3АТ « «Лектравы», } \\
\text { серия 30212 }\end{array}$ & $0,1657 \pm 0,0085$ \\
\hline 4 & $\begin{array}{l}\text { Цветки бессмертника } \\
\text { песчаного в пачке по 50 г }\end{array}$ & $\begin{array}{l}\text { 3АТ « «Лектравы», } \\
\text { серия 40212 }\end{array}$ & $0,1453 \pm 0,0068$ \\
\hline 5 & $\begin{array}{l}\text { Цветки бессмертника } \\
\text { песчаного в пачке по 20 г }\end{array}$ & $\begin{array}{l}\text { 3АТ ФФ «Виола», } \\
\text { серия 081011 }\end{array}$ & $0,1608 \pm 0,0083$ \\
\hline
\end{tabular}

В доступной нам литературе данные о наличии апигенина в другом исследуемом нами сырье, кроме бессмертника песчаного, отсутствуют. С целью проверки возможности стандартизации цветков бессмертника песчаного в МЛСРП по наличию и содержанию флавоноида апигенина, была изучена возможность стандартизации цветков бессмертника песчаного в присутствии каждого из исследуемых растительных компонентов.

Для подтверждения возможности стандартизации цветков бессмертника песчаного по наличию и содержанию флавоноида апигенина в присутствии указанного выше сырья были изготовлены модельные смеси с содержанием и без содержания цветков бессмертника песчаного.

Указанные модельные смеси были проанализированы в условиях разработанной хроматографической методики. Хроматограммы раствора сравнения апигенина, экстракта цветков бессмертника песчаного и экстрактов указанных смесей представлены на рисунке 1.

На хроматограммах раствора сравнения апигенина (А), экстракта цветков бессмертника песчаного (Б), растительной модельной смеси с содержанием бессмертника (В) присутствует пик апигенина, время выхода которого составляет 33,3 минуты. На хроматограмме растительной модельной смеси без содержания бессмертника песчаного (Г) данный пик отсутствует.

Таким образом, показана возможность качественной и количественной стандартизации цветков бессмертника песчаного в растительных смесях, содержащих плоды боярышника колючего, корни алтея лекарственного, корни солодки голой, корни цикория, корни одуванчика лекарственного, соплодия хмеля, траву пустырника, листья и цветки боярышника колючего, траву зверобоя продырявленного и семена льна по наличию и количественному содержанием флавоноида апигенина. Количественное содержание апигенина в модельной смеси с содержанием бессмертника песчаного в условиях нашего эксперимента составило $0,01516 \pm 0,0004 \%$ в перерасчете на высушенное сырье.

\section{Выводы:}

1. С использованием метода высокоэффективной жидкостной хроматографии разработана методология стандартизации цветков бессмертника песчаного в растительных смесях.

2. Показана возможность проведения качественной и количественной стандартизации цветков бессмертника песчаного по содержанию флавоноида апигенина в присутствии биологически активных веществ плодов боярышника колючего, корней алтея лекарственного, корней солодки голой, корней цикория, корней одуванчика лекарственного, соплодий хмеля, травы пустырника, листьев и цветков боярышника колючего, травы зверобоя продырявленного и семян льна. 


\section{Литература}

1. Государственная фармакопея СССР. - Вып.2: Общие методы анализа. Лекарственное растительное сырье / МЗ СССР - 11-е изд., доп. - М.: Медицина, 1989-400 с.

2. Гудзенко, А.В.. Використання речовин-маркерів - сучасний підхід до стандартизації багатокомпонентних лікарських засобів рослинного походження / Фармацевтичний журнал. 2011.-№ 5.-C. 87-91.

3. Куркина А.В. Исследование компонентного состава цветков Helichrysum arenarium (L.) Moench // Химия растительного сырья.-2011.-№2.-С. 113-116.

4. Куркина А.В. Новые подходы к стандартизации сырья бессмертника песчаного Helichrysum arenarium (L.) Moench // Традиционная медицина.-2010.-№ 1.-C. 45-49.

5. Растительные ресурсы СССР: Цветковые растения, их химический состав, использование. Семейство Asteraceae (Compositae) / Под ред. П.Д. Соколова.-СПб.: Наука, 1993.-351c.

6. Справочник «Компендиум-2011 - лекарственные препараты» / Под ред. В.Н. Коваленко, А.П. Викторова.-Киев: Морион, 2011.-2270 с.

7. Справочник лекарственных средств, зарегистрированных в Украине состоянием на 01.01.2011. Режим доступа: [www.Pharma-center.kiev.ua] (дата обращения 11.05.2011).

8. Clere, N.. Anticancer properties of flavonoids: roles in various stages of carcinogenesis / Cardiovasc. Hematol. Agents Med. Chem. 2011. Vol. 9(2). P. 62-77.

9. Cushnie T., Lamb A. Antimicrobial activity of flavonoids / Int. J. Antimicrob. Agents. 2005. Vol. 26(5). P. 343-356.

10. Sandhar H., Kumar B., Prasher S. et al. A review of phytochemistry and pharmacology of flavonoids / Int. Pharm. Sci.-2011. Vol. 1(1).-P. 25-41.

11. Shukla S., Gupta S. Apigenin: a promising molecule for cancer prevention // Pharm. Res. 2010. Vol. 27(6). P. 962-978.

12. Sroka Z., Kuta I., Cisowski W. et al. Antiradical activity of hydrolyzed and non-hydrolyzed extracts from Helichrysi inflorescentia and its phenolic contents / Z. Naturforsch.-2004.-Vol. 59, N.56.-P. 363-367.

$$
* * *
$$

Гудзенко Андей Викторович - кандидат фармачевтических наук, старший научный сотрудник Государственной лаборатории по контролю качества лекарственных средств ГУ «Институт фармакологии и токсикологии НАМН Украины». Область научных интересов: анализ многокомпонентных лекарственных средств растительного происхождения, хроматографические методы анализа, создание новых растительных лекарственных средств. Электронная почта: ganvi@yandex.ru.

Цуркан Александр Александрович - доктор фармачевтических наук, профессор, заведуюший Государственной лабораторией по контролю качества лекарственных средств ГУ «Институт фармакологии и токсикологии НАМН Украины».. Область научных интересов: анализ лекарственных средств, фитохимический анализ, хроматографические методы анализа, создание новых растительных лекарственных средств. Электронная почта: ganvi@yandex.ru. 